\title{
Towards an holistic understanding of disruptions in Operations Management
}

\author{
Patrik Jonsson* \\ School of Management and Economics, Växjö University, 35195 Växjö, Sweden
}

\begin{abstract}
The paper reviews the literature on maintenance management, integrates key dimensions of maintenance within a taxonomy of maintenance configurations, and explores the impact of differing configurations on contextual factors and operational performance. "Prevention", "hard maintenance integration" and "soft maintenance integration" were identified as key maintenance variables. Data were collected from 253 Swedish manufacturing companies, and three distinct clusters were identified. "Proactive Maintainers" emphasized preventive maintenance policies. "IT Maintainers" relied on computerized and company-wide integrated information systems for maintenance. "Maintenance Laggers" emphasized all maintenance dimensions to lesser extent than the others. The importance of maintenance prevention and integration differ between contexts. There were subtle performance differences across identified configurations, but preventive and integrated maintenance were more important for companies seeking competitive process control and flexibility. There existed no group with any great emphasis on all three maintenance dimensions, but attaining truly high performance may require a rare mix of the three dimensions. This mix of variables could constitute a hypothesized "World Class Maintenance" group. (C) 2000 Elsevier Science B.V. All rights reserved.
\end{abstract}

Keywords: Operations strategy; Maintenance; Productivity

\section{Introduction}

Holistic and proactive concepts, such as Lean Production, Just-in-Time, Total Quality Management (TQM), Concurrent Engineering and Supply Chain Management, are becoming important for companies seeking lean processes with short through-put time and zero defects. In most plants, the physical equipment is susceptible to failure through breakdown, deterioration in performance through age and use, and to obsolescence due to improvements in technology. However, the rising importance of "streamlin-

\footnotetext{
Tel.: +46-470-708797; fax: +46-470-83092.

E-mail address: patrik.jonsson@ehv.vxu.se (P. Jonsson).
}

ing" the processes and achieving process control and flexibility raises the cost of disturbances, and thus increases the need for reliable and consistent equipment without quality problems.

Error-free production with a minimum of stoppages, speed losses and quality defects are, however, still uncommon in industrial practice. Studies indicate overall equipment efficiencies (defined by Nakajima, 1988, as Availability $\times$ Performance efficiency $\times$ Rate of quality product) in the $40 \%$ to $70 \%$ range (Ljungberg, 1998; Ericsson, 1997), due to frequent process disturbances. These disturbances may lead to production losses and other indirect "hidden" costs (e.g. bad internal and external environment and safety of operators) that affect the 
overall performances of the organizations, for example in terms of higher direct production costs, longer through-put times, lower product quality and low customer service. A main reason for disruptions and unavailability in the production equipment is often considered to be the absence of proper maintenance (e.g. Nakajima, 1988; Ericsson, 1997). Therefore, maintenance should have an important role in operations management research and practices, yet this is not supported by current literature.

This paper seeks to fill some of the gaps in the literature on maintenance within operations strategy. The objectives are to review the literature on maintenance management, integrate key dimensions of maintenance within a taxonomy of maintenance configurations, and explore the impact of differing configurations on contextual factors and operational performance.

The growing use of advanced information and manufacturing technologies, such as electronic data interchange, enterprise resource planning, activity based costing, flexible manufacturing systems, robotics, and automatic handling systems, may help companies to achieve competitive process control and flexibility. Research in operations strategy has clearly shown that "learning organizations" with decentralized authority and empowered personnel are important prerequisites for achieving the full potential of investments in technology (e.g. Dean et al., 1992; Maffei and Meredith, 1994; Chen and Small, 1996; Boyer et al., 1997). There was only one study to be found on advanced manufacturing technology (Jonsson, 1999), which emphasized the importance of maintenance, and explained that it is a key variable for achieving high performance in advanced manufacturing technology environments.

Maintenance is also a key missing variable in existing works that have explored configurations of operations strategy and infrastructure, and their varied impact on performance. Those studies focusing on the competitive capabilities of operations strategy (Miller and Roth, 1994; Sweeney, 1991, 1993) are very well cited and have become "basic theory" in operations management. Another taxonomy describing manufacturing structure and infrastructure is also valuable for understanding the role of infrastructure in high-tech companies (Boyer et al., 1996). These configurations are important contributions to opera- tions strategy, but development of a maintenance taxonomy that links maintenance to operations strategy and performance would further the theory and practical development of operations strategies.

The paper is structured according to the objectives. First we discuss the development of the maintenance discipline, review the present maintenance literature, and identify three key variables within a cohesive maintenance management approach. Cluster analysis is then employed to identify an empirical maintenance taxonomy based on the three maintenance variables. Survey data is collected from seven Swedish manufacturing industries that together represent the majority of Swedish manufacturing companies. The similarities and differences of contextual factors and operational performance between the three identified clusters are explored by comparing means of the clusters. The paper ends with a discussion on the findings and limitations of the conducted study.

\section{A maintenance management framework}

This section discusses the development of the maintenance discipline and describes maintenance prevention, integration (soft and hard), and context in more detail.

\subsection{Present maintenance approaches and configura- tions}

The development of the maintenance discipline has been influenced by academic disciplines, such as industrial engineering, operations research and business administration. It started as an engineering topic, then operations research was included, and now also more emphasis is on the business and management disciplines. The development is driven by the need of industry, but as Sherwin (1999) states; "maintenance management has always developed somewhat behind the current requirements".

During the last decades much emphasis has been put on prevention and company-wide integration of maintenance. It is becoming too expensive to run the equipment until breakdown, and instead various preventive policies are developed. Maintenance activities are integrated into other business disciplines at 
various levels of the organization, and emphasis is changing towards its contribution to overall performance, instead of pure costs. This could be illustrated in the changed perspective from life-cycle costs to life-cycle profits of systems (e.g. Ahlmann, 1998).

The Terotechnology and Total Productive Maintenance (TPM) concepts have integrated maintenance into machine design, production and quality improvement processes of organizations (e.g. Nakajima, 1988; Rodriguez, 1990; Sherwin, 1999). Focus is on interaction between operators, maintenance crew and support staff. The objective is to continuously decrease the equipment losses and to improve the availability. The activities that previously were hierarchically controlled by the maintenance department are, to a greater extent, becoming parts of the responsibility of production teams, and being outsourced to external service providers (Martin, 1997). A basic idea of the ever more popular TPM concept is that the maintenance crew supports and trains the operators to do most of the daily equipment maintenance (e.g. cleaning, lubricating, tightening of bolts, adjusting, etc.) and that they themselves carry out only the more serious maintenance activities. It has finally transformed maintenance to an integrated organization and quality discipline, and has helped organizations to improve considerably their levels of overall utilization (Nakajima, 1989). This approach to maintenance is important for lean industrial manufacturing and the achievement of overall improvements. Patterson et al. (1996), for example, showed in a case study that TPM may lead to improved equipment availability, resulting in dramatically improved product cycle time, higher quality levels, less tied-up capital and increased overall productivity.

Although, proper maintenance approaches exist, neither maintenance practice nor theory are fully developed. Several papers have indicated that maintenance is a "low priority" discipline. Consultants have reported lists of maintenance-related problems (e.g. Smith, 1993), but most of these findings are based on limited cases and experience. Research (Wireman, 1990; De Jong, 1997; Jonsson, 1997; McKone et al., 1999), however, shows that maintenance is somewhat "under-developed", with lack of prevention and integration, in manufacturing companies on most continents.
There is also a lack of maintenance management configurations, such that could be useful to improve the understanding of the underlying dimensions of maintenance, and that could explain the effects of preventive maintenance and integrating maintenance into manufacturing. However, we have found a few conceptual maintenance typologies that emphasize prevention and/or integration. The basic "Terotechnology Model" and advanced modifications of it (e.g. Sherwin, 1999) call for feedback of information at several stages in the maintained system's life cycle, and link maintenance to quality and delivery capabilities. Geraerds (1992) presented the Eindhoven University of Technology (EUT) model that contained 14 sub-processes of maintenance and the Gits (1992) typology was based on "six steps to generate maintenance rules". Raouf (1994) took an "operations management" perspective, that was very similar to TPM, and described the maintenance process in terms of organizing (job design, standards, work measurement and project management), planning (maintenance capability, maintenance strategies and scheduling) and controlling (inventory control, material control, quality control and management for quality).

The content of, and relationship between, the prevention and integration variables are further discussed in Sections 2.2-2.4. In Section 2.2, various preventive maintenance policies are described. Hard (technology and IT) and soft (human and organizational) integration, that are discussed in Section 2.3, are important "enablers" for several preventive policies. The optimum choice of maintenance policy and integration mechanisms differs between contexts (Fig. 1). Preventive maintenance policies need to be supported by hard and soft integration. Computerized maintenance management information systems, for example, are quite important for condition monitoring and maintenance optimization, but also for decentralized improvement work that rely on empowerment and self-managed teams. Maintenance approaches in various contexts are discussed in Section 2.4.

\subsection{Preventive maintenance}

Preventive maintenance is considered a key variable of maintenance. Maintenance policies were tra- 


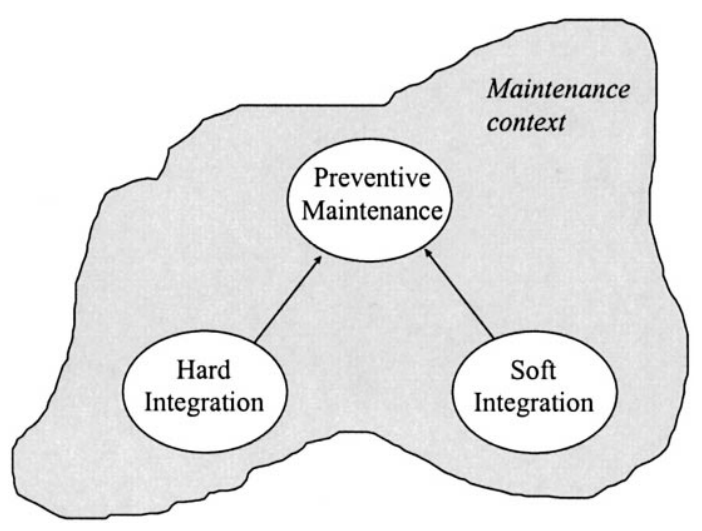

Fig. 1. Interaction between maintenance prevention and integration.

ditionally grouped as corrective (i.e. failure-based maintenance) or preventive in nature, and this structure is still relevant in most situations. The preventive policies can be further divided into use-based, condition-based, opportunity-based, design-out, and stand-by equipment maintenance (Pintelon and Gelders, 1992, p. 308).

The failure-based maintenance (FBM) approach is planned, but the action is reactive. No action will be taken until the event of failure. Typical corrective maintenance activities are emergency actions, repair, remedial and other un-scheduled maintenance. In many instances, temporary repairs may be made or redundant equipment used, so that the process can function again as soon as possible. Permanent repairs would have to be made at a later and more convenient time. Some activities may be delayed, due to redundant equipment or for cost reasons. Mobley (1990) referred to a study that showed that the costs for repair performed in this run-to-failure mode average about three times higher than the same repair made within a use-based or condition-based mode. The costs are high due to high cost of restoring equipment to an operable condition in a crisis situation, the secondary damage and safety/health hazards inflicted by the failure, and the penalty and loss of future orders associated with lost production. Corrective maintenance, or failure-based, can in some cases be the most appropriate policy. However, in the cases of purely random breakdowns and low breakdown costs, the failure-based maintenance policy may be the best policy. This is, however, not the case for most organizations. Where "random" failures are identified and, therefore, failure-based maintenance considered, deeper investigation usually shows that data is being collected at too high a level. The system may have a random breakdown pattern, but the components and parts within the system probably have increasing failure rates. A preventive maintenance policy should therefore be most appropriate. As Sherwin and Bossche (1993) state: "systems fail but we renew parts", so parts-level data are required for an accurate analysis.

Use-based (UBM) maintenance is a preventive policy and is carried out at predetermined intervals or corresponding to prescribed criteria and is intended to reduce the probability of failure or the performance degradation of an item. Its objective is to reduce the probability of breakdown by replacing or maintaining components after a specified number of units or time are used. The objective of all use-based maintenance is to lower the failure rate of equipment. If the failure rate is decreasing, usedbased maintenance would result in increasing the rate, and if the failure rate were constant, it would not alter it. In the traditional "bathtub curve", where the failure rate of the component or system is illustrated as a function of its life cycle, we find an increased failure rate in the wear-out region (Fig. 2). Preventive maintenance interventions that are carried out before this region will only cost money, without lowering the probability of failure of the system. The bathtub curve is criticized, though. Sherwin and Bossche (1993), for example, argued that there is a misunderstanding of the difference between the failure rate on system and parts levels. The bathtub curve illustrates the failure rate of systems, but com-

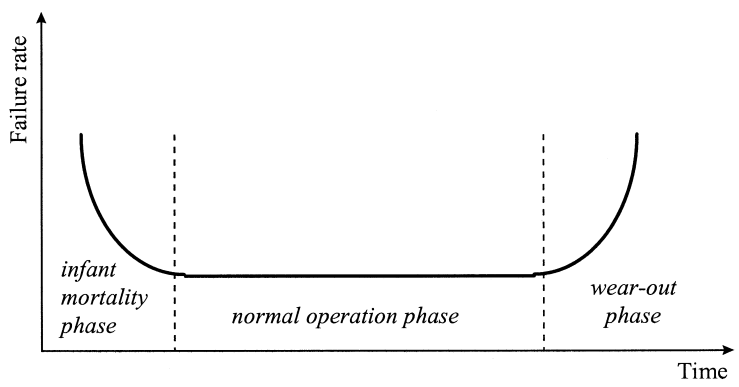

Fig. 2. The bathtub curve. 
ponents or parts are repaired, and the individual failure rates of the components have different shapes. A similar curve could, however, be drawn for a repairable system consisting of components (Pintelon and Gelders, 1992).

A positive effect of trend detection through data analysis carried out under use-based maintenance is that the analyst gains insight into the causes of failure, sees suitable preventive actions, and gets ideas for improvement that can help avoid future failures. These effects are often decreased as planning, failure detection and repair are seldom carried out by the same people. The schedules are not always based on primary maintenance modeling, but rather on scheduling plans from the machine deliverer. This can be quite precarious, as these schedules often are based on historical average data from different plants and environments, or on no data at all. Optimum application of the use-based maintenance policy requires proper data, often supported by comprehensive and integrated information systems. There is great potential in use-based maintenance, but its complexity, misunderstanding of systems-versusparts failures (as discussed earlier) and therefore lack of proper data, often makes use-based maintenance difficult to successfully apply. Therefore, use-based maintenance is one of the least applied preventive maintenance policies (Jonsson, 1997).

Condition-based maintenance (CBM) concerns preventive maintenance initiated as a result of knowledge of the changed condition of any particular item from routine or continuous monitoring. The causes of potential failures have to be identified since the key characteristics of underlying physical processes change from an initial value to a fatal value before failure occurs. Condition-based maintenance cannot be applied if such measurable "prognostic characteristics" cannot be found. The selected parameters are inspected continuously or with a certain frequency. Action, but often not overhaul, is taken if the measure exceeds the warning limit. Condition-based maintenance has been more important lately (Dekker, 1989; Geraerds, 1992; Mobley, 1990; Kelly, 1997; Pintelon and Gelders, 1992). This is driven by the fact that the average manufacturing company (no matter which industry) streamlines its processes, and emphasizes quality and flexibility capabilities to greater extent than before, which results in more serious consequences of failure and the need for early detection of potential disruptions.

Condition monitoring techniques, such as vibration monitoring, process-parameter monitoring, thermography and tribology, as well as operators, have key roles in condition-based maintenance policies. Visual inspection by operators can also be considered to be a condition-monitoring technique. Many of the potential failures can often be recognized by using the five human senses in order to continuously monitor the conditions of the machines. It is not uncommon that lubrication, routine cleaning, spannering and adjustment carried out by operators are the most profitable of all preventive maintenance policies (e.g. Idhammar, 1992). Studies presented by Maggard and Rhyne (1992) show that about $75 \%$ of maintenance problems could be prevented by operators at an early stage, by frequent looking, listening, smelling and tasting. This is the basic principle behind the operator involvement in TPM (see e.g. Nakajima, 1988). However, although it may delay the need for heavy maintenance, it does not eliminate all of it, and CBM based on human senses should therefore be combined with some other preventive policy. Collection and distribution of proper planning data should be critical for condition monitoring, as well as for the use-based policy.

Opportunity-based maintenance (OBM) is carried out during summer breaks, during other periods of low utilization, or when the equipment is idle, due to imbalance in planning or especially breakdown in other equipment. A negative result of maintenance during the shorter temporary stops is that the little maintenance jobs may be done rather than the big ones, which are repeatedly delayed.

Design-out maintenance (DOM) deals with improving the maintainability and reliability of the equipment in the design stage or by later physical modification of the equipment. Perhaps, design-out maintenance should not be viewed as a policy. It is of a more strategic nature than the other policies. Ahlmann (1998) emphasized the importance of taking a Life-Cycle Profit approach in the design, because a large proportion of the future defects are fixed in this early stage. Effectively integrating maintenance experiences in the design process requires feedback of data to purchasing and machine constructors and the use of cross-functional design teams. 
Despite the obvious importance of integrating maintenance at an early stage, we could not find many papers that had discussed this topic in any detail. Gotoh (1988), however, has presented a framework that builds maintenance reduction features into equipment at the design stage. His methods focus on reducing the time from new equipment design to stable operation, achieving effective balance between equipment maintenance, planning and improvement, and production of reliable equipment with lower life cycle costs.

Stand-by equipment (SBE) redundancy is an additional policy that typically will be used where the cost or risk of breakdown is extremely high, and where the equipment is not too expensive, or less expensive than buffer storage or alternative supplies. Failure in this type of equipment in particular may remain hidden until the item is in use. Preventive maintenance is therefore conducted through faultfinding activities at scheduled intervals. Hidden failures also affect parts of operating equipment, particularly trips and alarms (Hidden failures do represent a problem with other machines as well, though.). Partial redundancy, the ability to carry on at reduced output, is also an important aspect of redundancy.

Optimum policy is decided by its specific context, but the demand for short leadtimes, low tied-up capital, high quality and flexibility lead to increased costs for breakdown and consequently high costs for failure-based maintenance. Therefore, it is likely that a mix of preventive policies, rather than reliance on corrective maintenance (failure-based policies), would be preferable in most industrial manufacturing systems. Several preventive policies are based on specific organizational design and IT decision support, and, consequently, rely on hard and soft integration, discussed in the next sections. Thus, the following hypothesis is tested:

H1. Companies that focus on preventive maintenance policies are more likely to achieve high operational performance than companies that focus on corrective policies.

\subsection{Integration}

Integration of maintenance into manufacturing and the rest of the organization is partitioned into "hard integration" and "soft integration" variables. The "hard" issues deal with integration supported by technology and computers. "Soft" integration, on the other hand, deals with human and work organizational integration issues. The two integration variables are closely related to the prevention variable, and are considered important enablers for effective realization of preventive policies.

\subsubsection{Hard maintenance integration}

Advanced technology has several objectives and functions, such as transactional, geographical, "automational", analytical, informational, sequential, knowledge management, tracking and dis-intermediation (Davenport and Short, 1990). In terms of maintenance management the "hard" issues deal with Computerized Maintenance Management Systems (CMMS) of the MRO store (maintenance, repair and operating supplies) and scheduling of maintenance work, condition monitoring technologies, built-in test equipment, databases with reliability data on electronic and mechanical components, decision support systems (DSS), etc. (for a more thorough discussion on IT opportunities for maintenance see for example Pintelon et al., 1999). The objective of all "hard" maintenance issues is not primarily to integrate maintenance into the organization, but instead has an indirect effect.

A computerized maintenance management system is never a tool that can improve the competitiveness of an organization by itself, but rather it is a platform that collects and records the data for maintenance control and manufacturing process improvement, and supports the integration of functions and speeds up the flow of proper information. With a computerized maintenance management system integrated into the overall information system, the feedback from maintenance to production could be improved, and disturbance registration for continuous improvement could be conducted. De Smet et al. (1997), for example, showed the positive effects of computerized disturbance registration in a number of case studies. The study of Labib (1998) indicated that a data collection system that can gather relevant data is a prerequisite for achieving competitive strength in the operations environment. He emphasized the importance to link the computerized maintenance management system 
between production and maintenance departments, and to connect the computerized maintenance management system to alarms and bleepers via a programmable logic controller (PLC). This informational link between maintenance and manufacturing is critical for inducing process improvement and maintenance into company-wide issues. The existence of an integrated computerized maintenance management system is not enough in itself for prevention and proactive process improvement, but it enables organizations to implement it. The computerized maintenance management system contributes in two main ways. First, it enables automatic data capture and information transformation, leading to more accurate data quality. Secondly, it makes it easier for cross-functional design and project teams to base their decisions on facts. Thus, we test the following hypothesis:

H2. Companies that emphasize hard maintenance integration are more likely to achieve high operational performance than companies that do not.

\subsubsection{Soft maintenance integration}

Soft integration issues of maintenance deal with the structure and the actors in the organization. New technology allows plants to have fewer humans directly participating in the physical manufacturing processes. Increased need for quality, flexibility, innovation and service, as described by for example Chase et al. (1992), Corbet and Wassenhove (1993) and Hill (1993), affect the organizational design of manufacturing firms as well. These changes often lead to decreased need for standardization and for bureaucratic organizational structures, even in mass production firms. In organizations that compete on most manufacturing capabilities the highly specialized work force is exchanged for a multi-skilled and flexible one, with authority decentralized to the shop floor (e.g. Brulin and Nilsson, 1995). Spencer (1994) and others have shown that in these "new organizations" the horizontal flow of work across processes is more important than maintaining hierarchical control, and managerial boundaries between functional areas should be eliminated to ease coordination.

The human role in the "new manufacturing organization" is best described in the TQM literature, for example in "Deming's 14 points" (1986) or by Juran (1989),. Spencer (1994, p. 447) summarizes the role of employees in TQM as:

Employees are empowered to make decisions, build relationships, and take steps needed to improve quality within the system designed by management. Additional training and educational opportunities provide necessary skills for this broader role

In the Malcolm Baldridge Quality Award, the human actors are identified by human resource planning, employee involvement, employee education and training, employee performance and recognition, and employee well-being and fulfillment. Dean and Bednar (1994) emphasized that human resource planning has a small role in TQM. Employee involvement, empowerment and teamwork ideas are on the other hand corner stones in the concept. They are based on earlier organizational theories, such as those of Likert (1967), McGregor (1990) and Ouchi (1981). Employees, and in particular groups of employees, are given authority to make appropriate decisions for the particular situations they face. Education and training can be considered prerequisites for most of the other human aspects. The focus is on horizontal and cross-functional training, to make the employees multi-skilled, and not on creating vertical excellencies. Bowen and Lawler (1992) assert that the rationale of TQM is to help employees acquire a systems orientation via cross-functional career moves and horizontal reassignments. Performance and recognition is changed from individual to the team or system level. Waldman (1994) and Deming (1986) argue that performance is due mainly to system factors beyond an individual's control and that individual performance appraisal should be abolished. Deming further asserts that job satisfaction, job commitment and pride of workmanship are most important for employee fulfillment. The link between job fulfillment and continuous improvement, customer satisfaction and performance is considered to be strong among TQM enthusiasts.

The change of structure and human resource management in manufacturing firms affects the organization of maintenance and the way maintenance may be carried out. The decision to integrate maintenance into the manufacturing function and focusing on operators is a central theme in TPM, where au- 
tonomous production teams, small group activities and mounting a major effort in education and training are essential organizational building blocks. The aim is to make maintenance and process disruptions into company-wide issues, i.e. the activities should be performed by other than the maintenance department. The human aspects of maintenance activities are well illustrated by Shirose (1992) and Suzuki (1992). They argued that TPM changes the way operators think about equipment. This change can be realized when employees are empowered to make decisions, build relationships, and take steps needed to prevent breakdowns and improve quality within a system designed by management. Additional training and educational opportunities provide necessary skills for this broader role. Change, continuous improvement, and learning are encouraged. Ideally, all organizational members should be motivated to improve the status quo. The core idea is to create an environment for the efficient flow of information and continuous improvement by emphasizing integration, prevention and empowerment. Thus, we test the following hypothesis:

H3. Companies that focus on soft maintenance integration are more likely to achieve high operational performance than companies that do not.

\subsection{Contextual factors and operational performance of maintenance}

Various maintenance approaches are most likely to lead to high operational performance in different contexts. Here, contexts are described in terms of production process, industry, size and breakdown consequences.

In project or jobbing processes, redundancies and flexibility are built in. Machines are often idle and working hours flexible. In continuous processing, full standbys are rare and usually productive capacity is lost, but since some redundancies and inventories exist, it may be possible to survive breakdowns without preventive and optimized maintenance. The situation is more problematic for firms using hybrid batch processing to achieve both scale and scope economies. There, most machines are bottlenecks, inventory levels are minimized and delivery tight.
Studies of manufacturing strategy taxonomies (e.g. Ward et al., 1995) have shown correlation between manufacturing strategy groups and type of industry. None of these studies dealt with maintenance and integration, but industries are linked to production process choice and consequently also to maintenance.

Large firms may have more hierarchical, formalized and complex organizational structures than small firms. This would favor hard maintenance integration approaches, rather than soft. On the other hand, small firms probably favor jobbing processes and to a lesser extent line or continuous processes. This would lead overall to less need for preventive and company-wide integrated maintenance in small firms.

There are two aspects of breakdown consequences; stoppage costs and environmental risks. Positive correlation is expected between the severity of stoppage costs and degree of preventive and integrated maintenance. Breakdowns also create safety and environmental risks, causing direct and indirect losses. Maintenance could reduce this. Risks are difficult to measure and are therefore sometimes omitted. If they are serious they still lead to increased maintenance, though. Thus, we test:

H4. The effect of maintenance approaches on operational performance differs between contexts

\section{Methodology and measures}

\subsection{The sample}

The empirical data was collected through a mailed survey. Only plants with more than 50 employees were included in the sample. The survey was pretested, adjusted according to the feedback and sent to 747 Swedish maintenance or manufacturing managers in food, timber, paper, chemical, mechanical engineering and steel industries. These industries were chosen to get a representative distribution of companies between the most important Swedish manufacturing industries. The studied aspects of maintenance were considered important in most industries and, therefore, we sought as wide a selection as possible. 
To estimate the non-respondent bias the reasons given for not answering the questionnaire were analyzed, and respondents and non-respondents were compared regarding contextual factors (industry members and company size). Altogether 210 non-respondents were followed up by telephone calls. 39 firms had no manufacturing and another 30 said they were not interested in answering. 40 telephone interviews were carried out, but 101 non-respondents said that they were still thinking about answering the questionnaire, but did not want to answer by phone. The total number of relevant answers was 253 , which corresponds to a response rate of $36 \%$. Chi-square tests did not reveal any significantly different response rate $(p<0.05)$ between industries or between firms of different sizes.

\subsection{The measurement instrument}

The study contained measures on the "key maintenance dimensions", "contextual factors" and "operational performance". The empirical mainte- nance taxonomy was based on the three maintenance variables; preventive maintenance (PMAIN), hard maintenance integration (HMAIN), and soft maintenance integration (SMAIN), that correspond to the main areas of literature review in Sections 2.2-2.4. Table 1 shows the average, standard deviation, minimum and maximum for each measure.

Preventive maintenance is a mix of several policies and activities (here defined as strategic maintenance planning, condition-based maintenance, and other preventive policies). The respondents were asked to provide quantitative data for the number of hours spent on strategic maintenance planning, condition-based maintenance, other preventive maintenance policies and corrective maintenance activities (performed by anyone within the organization, for example maintenance, production or management personnel). The accumulated proportion spent on the three first approaches made up the PMAIN used in the present analysis (see Appendix A). There is always a possibility that the respondents forget to consider, or are not aware of, some preventive main-

Table 1

Descriptive data for measures used

\begin{tabular}{|c|c|c|c|c|}
\hline Measure & Average & Std. Dev. & Min. & Max. \\
\hline Preventive maintenance (PMAIN) & 51.45 & 23.97 & 1 & 5 \\
\hline Hard maintenance integration (HMAIN) & 1.71 & 1.05 & 1 & 4 \\
\hline Soft maintenance integration (SMAIN) & 3.61 & 0.81 & 1 & 5 \\
\hline \multicolumn{5}{|l|}{ Maintenance techniques } \\
\hline Condition monitoring & 0.16 & 0.47 & 0 & 2 \\
\hline Annual service & 0.38 & 0.64 & 0 & 2 \\
\hline Other preventive approaches & 0.95 & 0.83 & 0 & 2 \\
\hline Corrective maintenance & 0.85 & 0.91 & 0 & 2 \\
\hline Breakdown consequences & 2.11 & 1.56 & 1 & 6 \\
\hline Stop costs & $\begin{array}{l}\text { Median: } \\
\text { 1500-8000 USD/h }\end{array}$ & & & \\
\hline Defect rate/product performance & 4.28 & 1.36 & 1 & 6 \\
\hline Fast/dependable delivery & 3.85 & 1.48 & 1 & 6 \\
\hline Rapid product change & 3.19 & 1.55 & 1 & 6 \\
\hline Rapid volume/set-up change & 4.30 & 1.38 & 1 & 6 \\
\hline Production costs & 4.97 & 1.16 & 1 & 6 \\
\hline Tied up capital & 4.86 & 1.25 & 1 & 6 \\
\hline
\end{tabular}


tenance activities when estimating the overall hours of prevention in an organization. The predictive reliability of PMAIN was tested by measuring the correlation between PMAIN and the perceived importance of condition monitoring techniques, the five human senses, maintenance optimization, annual service, other preventive approaches (inspection), and corrective maintenance (measures see Appendix A). PMAIN was significantly positively correlated with maintenance optimization, annual service and other preventive maintenance techniques, and significantly negatively correlated with corrective maintenance (Table 2). The correlations with condition monitoring and the five human senses (which are heavily emphasized in TPM) were not significant. A reason for this should be that few companies had implemented these approaches. The test for predictive reliability showed that PMAIN measures several aspects of prevention, but it could still be somewhat biased because of lack of knowledge of the respondent. Another limitation of the measure, however, was that hours do not provide any indication of the effectiveness of a preventive maintenance program. Many hours spent on designing or carrying out a poorly designed program may not be effective.

HMAIN was measured as "the perceived level of computerization of the maintenance management information system" (see Appendix A). This was also a subjective measure, one which was easy to understand and estimate. More detailed measures, such as estimating the level of computerized communication of maintenance data between functions and processes, were not used, because of the expected differences between industries. More detailed measures could, however, have tracked other supportive technologies than information systems. A limitation of the measure was that it only gave high rating to companies with comprehensive information systems.
Such systems were most common in large companies (Bi-variate correlation between HMAIN and SIZE is statistically significant at the $p<0.01$ level). Investment in information systems, however, is considered the most important approach to hard integration. Consequently, the bias of the measure towards large companies was expected, and should not be a problem in the analysis.

SMAIN was measured in terms of high commitment to maintenance issues, high overall status of maintenance, high overall maintenance knowledge in the production department, and a high degree of maintenance improvement and disruption decreasing programs implemented in the production department. SMAIN was a six-point Likert summated scale based on four individual measures ("perceived commitment to maintenance in the production department", "perceived status of maintenance within the organization", "perceived level of knowledge about maintenance within the production department" and "level of maintenance process improvement and disruption decreasing programs"). The measure is presented in Appendix A. Cronbach's coefficient alpha is the most widely used measure for testing inter-item reliability when using summated scales (Sakakibara et al., 1993). The alpha of SMAIN was 0.70, thus the measure was considered internally reliable.

The inter-rater reliability was not tested because the questionnaire was considered too specific to be answered by anyone other than the maintenance manager. The content validity of the measures were secured since they were all based on extensive literature review and pre-tested before being sent out. No measure, however, had been used in previous studies and should be further developed. The construct validity of SMAIN was tested in factor analysis by principal components. The scales loaded on a single factor with Eigenvalue of 2.2, and all factor loadings were

Table 2

Bi-variate correlation between PMAIN and maintenance techniques

\begin{tabular}{lllllll}
\hline & $\begin{array}{l}\text { Condition } \\
\text { monitoring }\end{array}$ & $\begin{array}{l}\text { Five human } \\
\text { senses }\end{array}$ & $\begin{array}{l}\text { Maintenance } \\
\text { optimization }\end{array}$ & $\begin{array}{l}\text { Annual } \\
\text { service }\end{array}$ & $\begin{array}{l}\text { Other } \\
\text { preventive }\end{array}$ & $\begin{array}{l}\text { Corrective } \\
\text { maintenance }\end{array}$ \\
\hline PMAIN & 0.11 & 0.07 & $0.14^{*}$ & $0.17^{* *}$ & $0.21^{* *}$ & $-0.43^{* *}$ \\
\hline
\end{tabular}

* Significant at the $p<0.05$ level.

** Significant different at the $p<0.01$ level. 
in the 0.6 to 0.8 range, indicating that the measure was valid. It is, however, more relevant to consider the measure to be an index rather than a construct.

The maintenance context, which was compared between configurations, was measured in terms of production process, industry, number of employees, turnover in USD (US Dollars), breakdown consequences (six-point Likert scale from minor to very serious), stop costs in USD, and maintenance related time spent on strategic planning, prevention, on-condition and corrective maintenance.

Operational performance was mainly measured using the return on sales (ROS). It is an objective measure and was, therefore, difficult to compare between industries, or within industries competing on various markets. It is, however, still an aggregated measure of overall business performance. To measure the level of investment in quality and flexibility, two other measures were included. The level of investment in quality improvement programs was estimated through a five-point semantic scale (see Appendix A). The perceived importance of quality, flexibility and other manufacturing capabilities were measured on six point Likert scales (from not important to absolutely critical) in the last "performance measure".

\section{Findings}

There exist very few typologies of maintenance in literature and we could not find any complete empirically based classifications (taxonomy). The analysis presented here addresses this lack of maintenance taxonomy. The analyses and findings are presented in several steps. First, an empirical taxonomy of maintenance configurations was identified. Then contextual, maintenance, and operational performance factors were compared between the groups of companies.

The scales gave both parametric and non-parametric data. Therefore, different statistical techniques were used in the analysis. $F$-tests (ANOVA and Scheffe's pairwise comparison) were carried out when the data is presented in interval scales. Mean rank tests (Kruskal-Wallis and Wilcoxon-MannWhitney) were used when the data was on the ordinal level. Chi-square tests were used when the data was collected on a nominal scale.

\subsection{The maintenance taxonomy}

Cluster analysis was employed to identify the maintenance types from the variables SMAIN, HMAIN and PMAIN. The variables contained different scales (four-, five- and six-point Likert scales) and they were therefore standardized in the range between 0 and 1 before entry into the statistical analyses.

Ward's minimum variance cluster method was used to identify outliers and form appropriate numbers of clusters. There are several rules of thumb when finding an appropriate number of clusters. However, the most appropriate rule is to focus on the pronounced increase in the tightness of the clusters. Small changes of the clustering (agglomeration) coefficient when conducting hierarchical cluster analysis indicate that fairly homogeneous clusters are being merged, while joining two very different clusters resulted in a large percentage change in the coefficient (Hair et al., 1998). For our data, the change from two to three clusters resulted in a $53.9 \%$ change and the change from three to four clusters a $21.0 \%$ change. Thus, the three-cluster model was chosen. Non-hierarchical cluster analysis with seed points from the hierarchical results were used to fine-tune the results and present the final clusters, resulting in somewhat adjusted group members and cluster centers. To check the stability of the cluster solution, a second non-hierarchical analysis was performed, this time allowing the procedure to collect seed points at random. The cluster sizes were comparable and the final cluster solution is therefore considered consistent.

The final clusters should be distinct from each other and easy to interpret. We compared the clustering variables by group means using one-way ANOVA tests. Scheffe's pairwise comparison test was used to identify significant differences between individual pairs of groups on each of the three individual variables. Both tests indicated significant differences between the groups, indicating that the groups were distinct from each other (Table 3 ).

The three identified maintenance groups were named "Maintenance Laggers", "IT Maintainers" 
Table 3

Clusters and maintenance variables

\begin{tabular}{|c|c|c|c|c|}
\hline \multirow[t]{2}{*}{ Variables } & \multicolumn{3}{|l|}{ Clusters } & \multirow[t]{2}{*}{ Statistics } \\
\hline & $\begin{array}{l}\text { (1) Maintenance } \\
\text { Laggers }(n=123) \\
\text { Mean (Std. Dev.) }\end{array}$ & $\begin{array}{l}\text { (2) IT Maintainers } \\
(n=53) \\
\text { Mean (Std. Dev.) }\end{array}$ & $\begin{array}{l}\text { (3) Proactive } \\
\text { Maintainers }(n=77) \\
\text { Mean (Std. Dev.) }\end{array}$ & \\
\hline Soft maintenance & $3.37(0.72)[2,3]$ & $3.76(0.81)[1]$ & $3.92(0.72)[1]$ & $F=13.90, p<0.0001$ \\
\hline Hard maintenance & $1.23(0.48)[2]$ & $\mathbf{3 . 5 5}(0.50)[1,3]$ & $1.36(0.65)[2]$ & $F=372.42, p<0.0001$ \\
\hline $\begin{array}{l}\text { Preventive } \\
\text { maintenance }\end{array}$ & $2.41(0.71)[2,3]$ & $3.34(1.18)[1,3]$ & $\mathbf{4 . 4 8}(0.50)[1,2]$ & $F=165.74, p<0.0001$ \\
\hline
\end{tabular}

Note: Means and standard deviations are based on different scales. All measures were standardized (ranging from 0 to 1 ) before entry into the cluster analyses. $F$-statistics are derived from one-way ANOVAs. All variables are significantly different at the $p<0.01$ level. Scheffe's pairwise test of means was used for identifying pairwise differences. Numbers in brackets [ ] indicate the group numbers from which this group is significantly different at the $p<0.05$ level.

and "Proactive Maintainers". A short interpretation of the meaning of the groups is given below.

Cluster 1 - Maintenance Laggers: The first cluster contained almost half of the surveyed companies $(n=123)$. It was named "Maintenance Laggers" because it showed lower means on all clustering variables compared to both the other groups. The soft issues (commitment, status, knowledge and continuous improvement) of maintenance were emphasized on a medium level, which was significantly less than for both the other groups. The maintenance management information system (MMIS) was manual and separated from the rest of the organization. The relative use of preventive policies was significantly lower than in the other groups and is, therefore, the most reactive cluster.

Cluster 2 - IT Maintainers: This was the smallest group $(n=53)$, yet had the highest use of com- puterized and integrated information systems for maintenance. It emphasized soft maintenance issues and preventive policies to medium levels, which was more than for the "maintenance laggers", but less than for the "preventive maintainers".

Cluster 3 - Proactive Maintainers: The third group of companies focused on preventive maintenance policies and was also quite strong on the soft issues. The hard issues, however, were as under-developed similar to the "Maintenance Laggers".

It was interesting to note that no cluster emphasized all three variables to a great extent. The "IT Maintainers" emphasized all variables on at least medium level. The "Proactive Maintainers" emphasized SMAIN on a medium level and HMAIN on a low level. The "Maintenance Laggers" emphasized all variables to low or medium extents. Therefore, we posit the existence of a theoretical fourth group

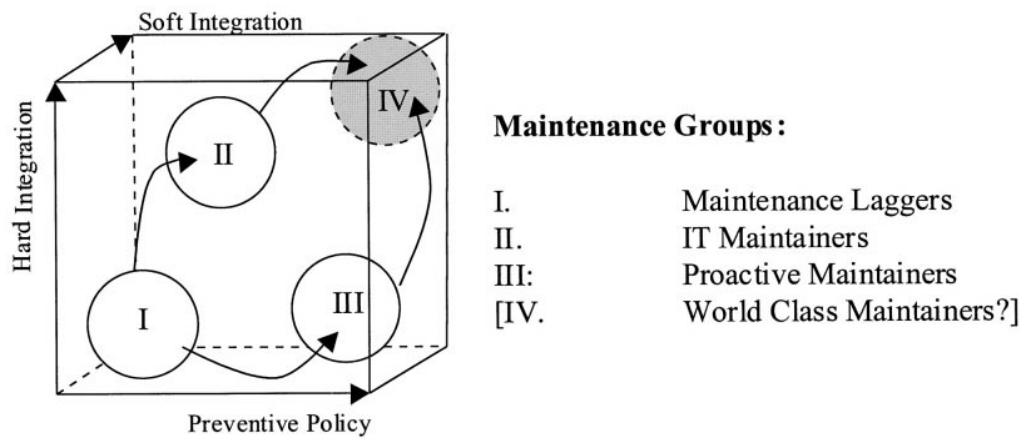

Fig. 3. A three-dimensional model of the maintenance taxonomy. 
(World Class Maintainers?) to Fig. 3, one which is strong on all three dimensions (the group was not included in the empirical analysis).

Such a theoretical group should exist, because process stability and preventive maintenance are important when shortening through-put times and decreasing tied-up capital in industry. Extensive preventive maintenance can hardly be applied without simultaneous emphasis on human, organizational and IT integration, which are the characteristics of the theoretical fourth group.

\subsection{Contextual and maintenance factors}

The next step of the analysis contained the identification of contextual similarities and differences between the clustered configurations. It was conceivable that the need for proactive policies and computerized and company-wide integrated information systems for maintenance was more critical in large companies with continuous mass production processes and high costs for disruption, than in smaller ones with batch or job-oriented processes. Table 4

Table 4

Contextual and maintenance factors by maintenance clusters

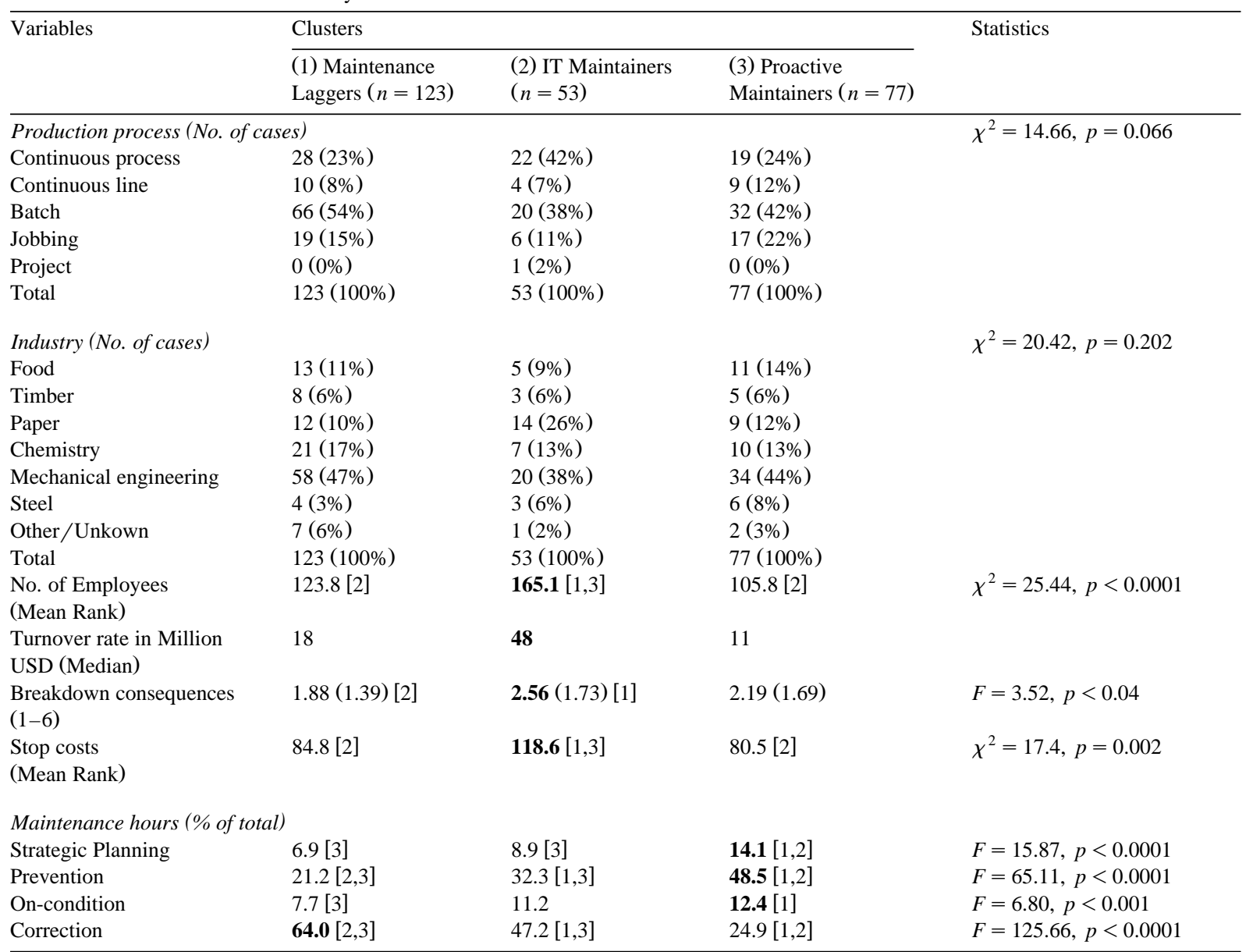

Note: Some of the tests are based on less than 253 cases, due to missing data. $\chi^{2}$ and $F$-statistics and associated $p$-values are derived from Chi-square, Kruskal-Wallis and one-way ANOVA tests. Wilcoxon-Mann-Whitney and Scheffe's tests of means were used for identifying pairwise differences. Numbers in brackets [ ] indicate the group numbers from which this group is significantly different at the $p<0.05$ level. Non-parametric tests, based on mean ranks, were used when scales were on an ordinal level. 
compares contextual and maintenance factors in terms of production process, industry, number of employees, turnover rate, breakdown consequences, stop costs, and maintenance time spent on various policies, between the three clustered groups.

The groups did not differ in terms of production process or industry membership, but the companies in the "IT Maintainers" group were significantly larger and had significantly higher breakdown costs compared to both the other groups. Despite the high breakdown costs, the "IT Maintainers" spent significantly less time on preventive policies than the "Proactive Maintainers". Almost half of their maintenance related time was spent on corrective activities, and eventhough it was difficult to state how much time should be spent on various policies, this figure seemed quite high. A rule of thumb presented by Wireman (1990) and Tomlingson (1993), for example, indicated that no more than $40 \%$ of the maintenance related man hours should be spent on correction in an average manufacturing plant.

\subsection{Operational performance}

The literature review and hypotheses in Section 2 on "a maintenance management framework" indicated that the maintenance variables; SMAIN,
HMAIN and PMAIN were important for achieving high performance. Consequently, the two groups of companies with high or medium emphasis on one or several of the variables could be expected to perform better than the "Maintenance Laggers" group with the lowest relative emphasis on all variables. The three measures of operational performance, i.e. return on sales, improvement programs, and manufacturing capabilities, were compared between the configurations. Table 5 shows the results of the analyses.

"IT Maintainers" have the highest profitability (return on sales) of all groups, which is significantly higher than the "Maintenance Laggers" on the $p<$ 0.02 level, or on the $p<0.06$ level compared to the "Proactive Maintainers". It is interesting to note the difference in profitability between "IT Maintainers" and "Proactive Maintainers". The former group is more profitable, eventhough they spent a relatively large proportion of time on corrective policies. Perhaps their emphasis on information technology and integration helped them to base the maintenance decisions on proper data and facts, resulting in more efficient and effective maintenance activities. The fact that the companies in the "IT Maintainers" group were larger than the other two groups may also have been a cause for higher profitability. An-

Table 5

Outcome and manufacturing strategy factors by maintenance clusters

\begin{tabular}{|c|c|c|c|c|}
\hline \multirow[t]{2}{*}{ Variables } & \multicolumn{3}{|l|}{ Clusters } & \multirow[t]{2}{*}{ Statistics } \\
\hline & $\begin{array}{l}\text { (1) Maintenance } \\
\text { Laggers }(n=123) \\
\text { Mean (Std. Dev.) }\end{array}$ & $\begin{array}{l}\text { (2) IT Maintainers } \\
(n=53) \\
\text { Mean (Std. Dev.) }\end{array}$ & $\begin{array}{l}\text { (3) Proactive } \\
\text { Maintainers }(n=77) \\
\text { Mean (Std. Dev.) }\end{array}$ & \\
\hline Return on sales, ROS (\%) & $10.03(9.31)[2]$ & $16.19(11.89)[1]$ & $10.55(8.05)$ & $F=4.64, p=0.01$ \\
\hline Improvement programs (Mean Rank) & $111.2[2,3]$ & $147.2[1]$ & $137.0[1]$ & $\chi^{2}=12.69, p=0.02$ \\
\hline Fast/dependable delivery & $4.12(1.27)[3]$ & $4.30(1.61)$ & $4.77(1.17)[1]$ & $F=5.80, p<0.01$ \\
\hline Rapid product change & $3.68(1.48)[3]$ & $3.81(1.58)$ & $4.22(1.37)[1]$ & $F=3.21, p<0.05$ \\
\hline Rapid vol./set-up change & $2.88(1.50)[3]$ & $3.45(1.57)$ & $3.59(1.50)[1]$ & $F=5.72, p<0.01$ \\
\hline Production costs & $4.83(1.26)$ & $5.25(0.88)$ & $4.96(1.19)$ & $F=2.30, p=0.10$ \\
\hline Tied up Capital & $4.16(1.39)$ & $4.69(1.25)$ & $4.30(1.32)$ & $F=2.89, p=0.06$ \\
\hline
\end{tabular}

Note: Some of the tests are based on less than 253 cases due to missing data. $\chi^{2}, F$ statistics and associated $p$-values were derived from Kruskal-Wallis and one-way ANOVAs. Wilcoxon-Mann-Whitney and Scheffe's test of means were used for identifying pairwise differences. Numbers in brackets [ ] indicate the group numbers from which this group is significantly different at the $p<0.05$ level. Non-parametric tests, based on mean ranks, were used when scales were on an ordinal level. 
other explanation to the subtle profitability differences could be that the measure of profitability is a single objective measure, which was difficult to compare between companies competing in various markets.

When it came to more indirect performance variables, such as the establishment of quality and process improvement programs, and an emphasis on multiple manufacturing capabilities, the pattern was somewhat different and more synchronized with the hypotheses and our expectations. Here, we could not identify any significant difference between "IT Maintainers" and "Proactive Maintainers", but the "Maintenance Laggers" emphasized improvement programs and the manufacturing capabilities to a lesser extent than the two other groups (however, all the differences are not significant). Production costs (costs) and defect rates (quality) were the two most important capabilities, while rapid product change and rapid volume/set-up change (flexibility) are the two least important capabilities for all groups. The "Proactive Maintainers" showed the highest mean values for the quality, fast and dependable delivery (delivery), and flexibility variables. They were significantly higher than those for the "Maintenance Laggers". Consequently, process control and flexibility seemed to be more important for companies with preventive maintenance policies, than for those relying on more corrective policies.

\section{Conclusions and comments}

Although the impact of maintenance on the performances of manufacturing companies may be considerable, maintenance strategy has not yet received full attention in practice or in research. The findings of the current paper provide a framework for understanding the role of preventive and integrated maintenance, and for further research on the link between maintenance and performance. It indicates that maintenance prevention and integration are important for the manufacturing strategy of a company, but that the mix of prevention and integration could differ between contexts. Those consultants and researchers that have promoted benefits of maintenance often fail to identify contextual issues that may make adoption difficult or ineffective. It is important that managers do not consider specific maintenance practices to be appropriate for all situations.

In the current paper, manufacturing companies were clustered into three configurations, based on their emphases on preventive maintenance, hard maintenance integration and soft maintenance integration. The identified taxonomy showed that there was a variety of maintenance investment approaches and that each configuration could be profitable by itself.

Further analysis revealed that preventive and company-wide integrated maintenance were important for companies, with high breakdown consequences and stop costs, which seek competitive process control and flexibility. It was proposed that maintenance should be most important in lean manufacturing organizations with "streamlined" processes, but this should be further researched.

Profitability was highest for the group with heavy investments in information technology (hard integration). The link between maintenance and profitability, however, should be further analyzed. The measure could not identify proper indications of performance differences or similarities between configurations. A limitation of the conducted study was that the profitability was measured with only one objective measure, which was difficult to compare across industries. Maintenance may not directly lead to high performance, but may affect mediating variables and should be important to a greater or lesser degree in various manufacturing and marketing contexts. A specific approach is not good for all situations and it is believed that contextual studies are important to further improve the understanding of maintenance strategy in different environments. An unexplored research question involves identifying the underlying variables necessary for achieving high performance within respective maintenance configurations. The present study proposes that: "preventive and integrated maintenance is quite important for IT Maintainers and Proactive Maintainers, in order to achieve high performance, but that it is of less importance for Maintenance Laggers". This hypothesis could be addressed by identifying contextual variables, developing more complex measures of operational performance, and conducting regression analysis. Separate regression models within respective configurations, with independent contextual and 
maintenance variables and dependent operational performance variables, could then be employed.

Another finding was that none of the clusters contained companies that simultaneously emphasized all three dimensions to any great extent. Therefore, it is interesting to analyze whether a high emphasis on all dimensions necessarily relates to increased effectiveness. This question could be studied in a broad based study, similar to the one conducted in this paper, but that focuses on companies in heavy industries with serious breakdown consequences and high stop costs (i.e. companies that need preventive and integrated maintenance).

The measures used have some drawbacks and need to be further developed in future research. All measures could be more detailed and expressed as multiple scales. This is especially true for HMAIN, which could cover other aspects than the information system. PMAIN focuses purely on hours spent on policies, but does not tell how well policies are carried out. SMAIN covers various aspects of soft integration. It could be extended and split into a set of related scales.

\section{A. Measure listing}

\section{A.1. Preventive Maintenance (PMAIN)}

Estimate the proportion of maintenance related time (man-hours) spent on strategic planning, oncondition, planned preventive activities or corrective activities (Please, distribute $100 \%$ of the maintenance time).

[A] Planning, strategy and tactical issues $\%$

[B] Planned preventive maintenance $\%$

[C] Condition monitoring $\%$

[D] Corrective maintenance $\%$

Note: PMAIN measures the accumulated proportion of time spent on "Planning, strategy and tactical issues", "Planned preventive maintenance" and "Condition monitoring" on a five-point scale (1) " $0-20 \%$ of the total time spent on alternatives A, B and C"; (2) " $81-100 \%$ of the total time spent on alternatives $\mathrm{A}, \mathrm{B}$ and $\mathrm{C}$ ".

\section{A.2. Hard Maintenance Integration (HMAIN)}

Which are the characteristics of your Maintenance Management Information System? (Please, mark one alternative).

1. None, or manual system

2. Partly computerized system operated from a separate computer system and network

3. Fully computerized system operated from a separate computer and network

4. Fully computerized system integrated into the overall Management Information System

Note: HMAIN is on ordinal level, but included in the cluster analysis as interval scaled.

\section{A.3. Soft Maintenance Integration (SMAIN) - Six-} point summated Likert scales

[A] Estimate the level of commitment to maintenance issues in the production department (from "very low" to "very high")

[B] Estimate the perceived status of maintenance within the organization (from "very low" to "very high")

[C] Estimate the level of general maintenance knowledge within the production department (from "only maintenance department has knowledge" to "the entire production department has very good knowledge and understanding of maintenance")

[D] Estimate the existence of maintenance process improvement programs (from "no activity has been carried out for several years" to "process improvement has for several years had a central role in maintenance. All employees are involved")

\section{A.4. Improvement Programs}

"How do you work with process and quality improvement programs? (Please, mark one alternative)"

[I] No specific quality improvement activity has been conducted during the last years. 
[II] Quality improvement activities have received increased importance, but are still scarce.

[III] Some employees work with quality improvement issues.

[IV] Continuous quality improvement activities are important parts of the corporate strategy-several employees participate.

[V] Quality has a central role in the organizationimprovement programs have for several years been important for continuously improving production and maintenance-all employees participate.

\section{A.5. Maintenance Techniques}

"Which are the most important "maintenance techniques" in your company? (Mark the most important with " 1 " and the second most important with " 2 ")"

[A] Condition monitoring, based on technology (vibration, termography, tribology, process control, ultrasonic sound, etc.)

[B] Condition monitoring based on human senses (eyesight, hearing, feeling, smelling, tasting)

[C] Failure and reliability based optimization

[D] Annual service

[E] Other scheduled preventive maintenance

(scheduled inspection, etc.)

[F] Corrective maintenance

[G] Other approach

\section{A.6. Manufacturing Strategy}

"For your manufacturing plant, to what extent do you emphasize the following issues: (Six-point Likert scales from "not important" to "the issue has had highest priority during several years")"
[A] Defect rate/product performance
[B] Fast/dependable delivery
[C] Rapid product change
[D] Rapid vol./set-up change
[E] Production costs
[F] Tied up Capital

\section{References}

Ahlmann, H., 1998. Servicing and maintenance. In: Elfving, G. (Ed.), ABB Industrial Manual. ABB, Västerås, Sweden, pp. 1063-1116.

Boyer, K., Ward, P.T., Leong, K.G., 1996. Approaches to the factory of the future: an empirical taxonomy. Journal of Operations Management 14 (4), 297-313.

Boyer, K., Leong, K.G., Ward, P.T., Krajewski, L.J., 1997. Unlocking the potential of advanced manufacturing technologies. Journal of Operations Management 15 (4), 331-347.

Brulin, G., Nilsson, T., 1995. Läran om arbetets ekonomi: om arbete och produktivitet i modern produktion. Tiden, Kristianstad, Sweden.

Bowen, D.E., 1992. Total quality-oriented human resources management. Organizational Dynamics, 29-41.

Chase, R.B., Kumar, K.R., Youngdahl, W.E., 1992. Service-based manufacturing: the service factory. Production and Operations Management 1 (1), 175-184.

Chen, I.J., 1996. Planning for advanced manufacturing technology: a research framework. International Journal of Operations and Production Management 16 (5), 4-24.

Corbet, C., Wassenhove, L., 1993. Trade offs? What trade offs? competence and competitiveness in manufacturing strategy? California Management Review 35 (4), 107-122.

Davenport, T.H., 1990. The new industrial engineering: information technology and business process redesign. Sloan Management Review, 11-27.

De Jong, E., 1997. Maintenance practices in manufacturing SMEs, (Working paper, National Key Centre for Advanced Materials Technology, Monash University, Australia).

De Smet, R., Gelders, L.F., Pintelon, L.M., 1997. Case studies on disturbance registration for continuous improvement. Journal of Quality in Maintenance Engineering 3 (2), 91-108.

Dean, J.W, Bednar, D.A., 1994. Management theory and total quality: improving research and practice through theory development. The Academy of Management Review 19 (3), 392 418.

Dean, J.W., Yoon, S.J., Susman, G.I., 1992. Advanced manufacturing technology and organization structure: empowerment or subordination? Organization Studies 3 (2), 203-229.

Dekker, R., 1996. Applications of maintenance optimisation models: a review and analysis. Reliability Engineering and Systems Safety 51 (2), 229-240.

Deming, W.E., 1986. Out of the Crisis. MIT Press, Cambridge, MA.

Ericsson, J., 1997. Störningsanalys av tillverkningssystem: ett viktigt verktyg inom lean production, $\mathrm{PhD}$ Thesis (Lund University, Department of Production and Materials Engineering Lund, Sweden).

Geraerds, W.M.J., 1992. The EUT maintenance model. International Journal of Production Economics 24 (2), 209-216.

Gits, C.W., 1992. Design of maintenance concepts. International Journal of Production Economics 24 (2), 217-226.

Gotoh, F., 1988. Equipment Planning for TPM: Maintenance Prevention Design. Productivity Press, Cambridge, MA. 
Hair, J.F., Anderson, R.E., Tatham, R.L., Black, W.C., 1998. Multivariate Data Analysis. Prentice-Hall, London.

Hill, T, 1993. Manufacturing Strategy: The Strategic Management of the Manufacturing function. MacMillan, London.

Idhammar, B., 1992. Underhållets hörnstenar-rationellt underhåll I. Idhammars Förlag, Södertälje, Sweden.

Jonsson, P., 1997. The status of maintenance management in Swedish manufacturing firms. Journal of Quality in Maintenance Engineering 3 (4), 233-258.

Jonsson, P., 1999. Achieving the potential benefits of advanced manufacturing technology — a study of Swedish metal working companies. In: Kocaoglu, D.F., Anderson, T.R. (Eds.), Technology and Innovation Management, Section-18: Manufacturing Management. Portland State University, OR, pp. 485-492.

Juran, J., 1989. Juran on Leadership for Quality. Free Press, NY.

Kelly, A., 1997. Maintenance Strategy: Business-Centred Maintenance. Butterworth-Heinemann, Oxford.

Labib, A.W., 1998. World-class maintenance using a computerized maintenance management system. Journal of Quality in Maintenance Engineering 4 (1), 66-75.

Likert, R., 1967. The Human Organization: Its Management and Value. McGraw-Hill, NY.

Ljungberg, Ö., 1998. Measurement of OEE as a basis for TPM activities. International Journal of Operations and Production Management 18 (5), 495-507.

Maffei, M.J., Meredith, J., 1994. The organizational side of flexible manufacturing technology: guidelines for managers. International Journal of Operations and Production Management 14 (8), 17-34.

Maggard, B.N., Rhyne, D.M., 1992. Total productive maintenance: a timely integration of production and maintenance. Production and Inventory Management Journal 33 (4), 6-10.

Martin, H., 1997. Contracting out maintenance and a plan for future research. Journal of Quality in Maintenance Engineering 3 (2), 81-90.

McGregor, D., 1990. The Human Side of Enterprise. McGraw-Hill, NY.

McKone, K.E., Schroeder, R.G., Cua, K.O., 1999. Total productive maintenance: a contextual view. Journal of Operations Management 17, 123-144.

Miller, J.G, Roth, V.R., 1994. A taxonomy of manufacturing strategies. Management Science 40 (3), 285-304.

Mobley, R.K., 1990. An Introduction to Predictive Maintenance. Van Nostrand Reinhold, NY.

Nakajima, S., 1988. Introduction to TPM. Productivity Press, Cambridge.

Nakajima, S., 1989. TPM Development Program-Implementing Total Productive Maintenance. Productivity Press, Portland.

Ouchi, W., 1981. Theory “Z”. Addison-Wesley, Reading, MA.
Patterson, J.W., Fredendall, L.D., Kennedy, W.J., McGee, A., 1996. Adapting total productive maintenance to Asten. Production and Inventory Management Journal 37 (4), 32-37.

Pintelon, L.M., Gelders, L.F., 1992. Maintenance management decision making. European Journal of Operational Research 58, 301-317.

Pintelon, L., Du Preez, N., Van Puyvelde, F., 1999. Information technology: opportunities for maintenance management. Journal of Quality in Maintenance Engineering 5 (1), 9-24.

Raouf, A., 1994. Improving quality productivity through maintenance. International Journal of Operations and Production Management 14 (7), 44-52.

Rodriguez, J.R., 1990. Total productive maintenance. In: The Ernst \& Young Quality Improvement Consulting Group (Ed.), Total Quality: A Manager's Guide for the 1990s. Kogan Page, London, pp. 152-161.

Sakakibara, S., Flynn, B.B., Schroeder, R.G., 1993. A framework and measurement instrument for just-in-time manufacturing. Production and Operations Management 2 (3), 177-194.

Sherwin, D.J., 1999. A Review of Past and Current Overall Models for Maintenance Management. Working Paper, Växjö University, Växjö, Sweden.

Sherwin, D.J., 1993. The Reliability, Availability and Productiveness of Systems. Chapman \& Hall, London.

Shirose, K., 1992. TPM for Workshop Leaders. Productivity Press, Cambridge, MA.

Smith, A., 1993. Reliability-Centered Maintenance. McGraw-Hill, NY.

Spencer, B.A., 1994. Models of organization and total quality management: a comparison and critical evaluation. The Academy of Management Review 19 (3), 446-471.

Suzuki, T., 1992. New Directions for TPM. Productivity Press, Cambridge, MA.

Sweeney, M., 1991. Towards a unified theory of strategic manufacturing management. International Journal of Operations and Production Management 11 (8), 6-22.

Sweeney, M., 1993. Strategic manufacturing management: restructuring wasteful production to world class. Journal of General Management 18 (3), 57-76.

Tomlingson, P.D., 1993. Effective Maintenance: The Key to Profitability. Van Nostrand Reinhold, NY.

Waldman, D.A., 1994. The contributions of total quality management to a theory of work performance. The Academy of Management Review 19 (3), 510-536.

Ward, P.T., Duray, R., Leong, G.K., Sum, C., 1995. Business environment, operations strategy, and performance: an empirical study of Singapore manufacturers. Journal of Operations Management 13 (2), 99-115.

Wireman, T., 1990. World Class Maintenance Management. Industrial Press, NY. 